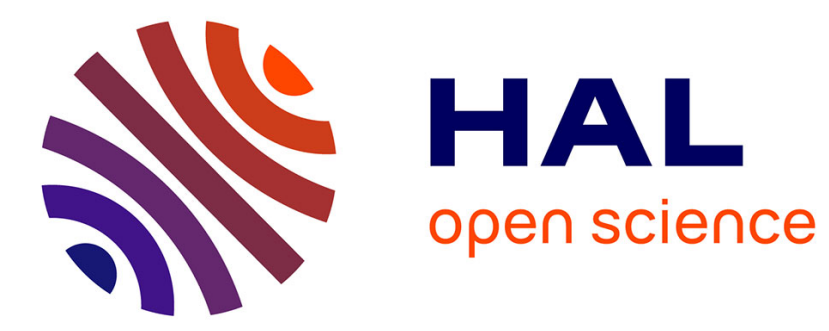

\title{
Origin of epoxies embrittlement during oxidative ageing
}

\author{
Esteve Ernault, Emmanuel Richaud, Bruno Fayolle
}

\section{To cite this version:}

Esteve Ernault, Emmanuel Richaud, Bruno Fayolle. Origin of epoxies embrittlement during oxidative ageing. Polymer Testing, 2017, 63, pp.448-454. 10.1016/j.polymertesting.2017.09.004 . hal-01593556

\section{HAL Id: hal-01593556 https://hal.science/hal-01593556}

Submitted on 26 Sep 2017

HAL is a multi-disciplinary open access archive for the deposit and dissemination of scientific research documents, whether they are published or not. The documents may come from teaching and research institutions in France or abroad, or from public or private research centers.
L'archive ouverte pluridisciplinaire HAL, est destinée au dépôt et à la diffusion de documents scientifiques de niveau recherche, publiés ou non, émanant des établissements d'enseignement et de recherche français ou étrangers, des laboratoires publics ou privés. 


\title{
Origin of epoxies embrittlement during oxidative ageing
}

\author{
Esteve Ernault, Emmanuel Richaud*, Bruno Fayolle \\ PIMM UMR 8006, Arts et Métiers ParisTech, CNAM, CNRS, 151 bd de l'Hôpital, Paris, France
}

\begin{abstract}
A B S T R A C T
Thermal oxidation of three epoxy resins prepared from flexible or rigid prepolymers and hardeners was studied by monitoring epoxy mechanical and physical changes. The physical changes were followed by mass measurements, glass transition temperature using DSC and sub-glass $\beta$ transition using DMA. It was put in evidence that embrittlement is not directly associated to $T_{g}$ or mass loss changes since epoxy network based on isophorone diamine (IPDA) hardeners were shown to undergo mainly a chain scission at the beginning of exposure process whereas epoxy network based on trioxatridecane diamine (TTDA) hardeners exhibits a crosslinking process with a significant mass loss. The only common feature for both epoxy systems to understand embrittlement is the drop of amplitude of $\beta$ transition with oxidation.
\end{abstract}

Epoxy diamine

Oxidation

Failure properties

\section{Introduction}

Epoxy family cover a large diversity of polymer networks differing by the nature of resins and hardeners commercially available. Depending on resin and hardener used, range of $T_{g}$ can vary from $60{ }^{\circ} \mathrm{C}$ up to $250{ }^{\circ} \mathrm{C}$ for instance tris(4-hydroxyphenyl) methane triglycidyl ether (Tactix 742) and diglycidyl ether of bisphenol A (Tactix 123), with an aromatic diamine hardener: 4,4diaminodiphenyl sulfone [1,2].

In many applications such as composites for aeronautical components, a peculiar concern is associated to long term ageing effect since oxidation affects strongly the epoxy mechanical properties, especially the failure properties. In this context, epoxy lifetime is often empirically related to mass loss induced by oxidation. However, to predict lifetime with an accurate manner for all epoxy networks, embrittlement mechanisms associated to oxidation have to be deeply studied. Since embrittlement process corresponds to failure properties drop, let us recall some approaches relating these properties with epoxy networks characteristics.

Failure properties, especially strain at break or toughness $\mathrm{G}_{\mathrm{IC}}$, are governed by the capacity to promote plastic deformation. Even if the relationships between structure and plastic deformation for epoxy networks in glassy state have been studied since the seventies [3-8], the molecular origin for plastic deformation mechanisms in the epoxy networks still is an open question. The variety of epoxy networks studied in the literature and the difficulties to

\footnotetext{
* Corresponding author

E-mail address: emmanuel.richaud@ensam.eu (E. Richaud).
}

investigate plastic deformation zone can explain this lack of consensus in literatures. Several approaches have been proposed to understand the molecular aspects of plastic deformation in epoxy networks:

- Plastic deformation is promoted if glass transition is close to mechanical test temperature. In other words, plasticity is associated to cooperative mobility.

- Plastic deformation is linked to molar mass between crosslinks $\left(\mathrm{M}_{\mathrm{C}}\right)$. In this approach, plastic deformation obeys the relationships proposed in rubber elasticity theory where deformation at failure is associated to the chain extensibility limit. Indeed, several authors have put in evidence that epoxy network fracture energy is proportional to $\mathrm{M}_{\mathrm{C}}^{1 / 2}$ [9]. However, an opposite trend has been witnessed by Urbaczewsk-Espuche et al. [10].

- Plastic deformation is associated to secondary transition below $\mathrm{T}_{\mathrm{g}}$, which is often called $\beta$ transition. The $\beta$ transition in networks based on DEGBA is attributed to local motions linked to hydroxyether segments [11]. As a result, plastic deformation (cooperative motions) is activated by this local mobility for a given state stress.

In this paper, we propose to follow epoxy networks modifications during oxidation in terms of glass transition and $\beta$ transition and to relate these modifications to embrittlement process. For this purpose, we have chosen three epoxy networks: two systems having a relatively low $\mathrm{T}_{\mathrm{g}}$ (DGEBA/TTDA and DGEBU/IPDA, 69 and $60{ }^{\circ} \mathrm{C}$ respectively) and a system having a high $\mathrm{T}_{\mathrm{g}}$ (DGEBA/IPDA, $166{ }^{\circ} \mathrm{C}$ ). Furthermore, it has been witnessed that among these 
systems, one system undergoes mainly chain scission (DGEBA/ IPDA) whereas the other undergoes mainly crosslinking [12]. The final objective is then to propose a common scenario to explain embrittlement induced by oxidation for epoxy networks.

\section{Experimental}

\subsection{Materials}

Two kinds of prepolymers are used.

- The diglycidyl ether of bisphenol A (DER 332, CAS 1675-543-ref 31185 supplied by Sigma Aldrich) has a degree of polymerization $\mathrm{n} \sim 0$ and a number average molecular mass equal to $340 \mathrm{~g} / \mathrm{mol}$.

- The diglycidyl ether of 1,4-butanediol named DGEBU (CAS 242579-8-ref 220892 by Sigma Aldrich) has an average molecular mass of $202.25 \mathrm{~g} / \mathrm{mol}$

Two kinds of hardeners have been chosen:

- The isophorone diamine here named IPDA (CAS 2855-13-2-ref 118184 by Sigma Aldrich, $\mathrm{M}=170.3 \mathrm{~g} / \mathrm{mol}$ ).

- The 4,7,10-trioxa-1,13-tridecanediamine here named TTDA (CAS 4246-51-9-ref 369519 by Sigma Aldrich, $M=220.3 \mathrm{~g} / \mathrm{mol}$ ).

The chemical structure of chemicals is given in Fig. 1.

These components were mixed in stoichiometric ratio and fully cured checked by the total disappearance of exothermal signal and by FTIR from the loss of $914 \mathrm{~cm}^{-1}$ peak attributed to epoxide group. Details of films preparation, thermal characterization of the cure and glass transition of final networks obtained can be found elsewhere [13]. Thin films have been processed in heating press.

Thermal ageing under atmospheric air was performed in ventilated ovens (calibrated at $\pm 3{ }^{\circ} \mathrm{C}$ ) at $110{ }^{\circ} \mathrm{C}$. Films having a thickness lower than $100 \mu \mathrm{m}$ to avoid diffusion limited oxidation were periodically removed for analysis.

\subsection{Characterization}

\subsubsection{Oxidative products concentrations}

To assess oxidative products concentration during exposure, FTIR spectroscopy in transmission mode was performed on free standing films using a Frontier spectrophotometer (PerkinElmer) in the 550 to $4000 \mathrm{~cm}^{-1}$ wavenumber range by averaging 16 scans with a $4 \mathrm{~cm}^{-1}$ resolution. Spectra were interpreted using the Spectrum<smiles>CC(C)(c1ccc(OCC2CO2)cc1)c1ccc(OCC2CO2)cc1</smiles>
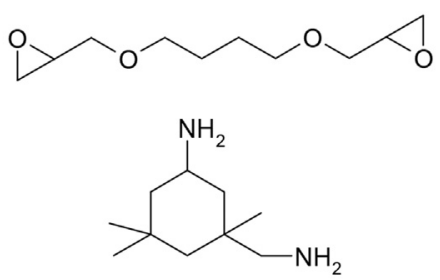

$$
\mathrm{H}_{2} \mathrm{~N} \sim \mathrm{O} \sim \mathrm{NH}_{2}
$$

Fig. 1. Chemical structure of (a) diglycidyl ether of bisphenol A (DER332), (b) diglycidyl ether of 1,4-butanediol (DGEBU) (c) isophorone diamine (IPDA) (d) 4,7,10-trioxa-1,13tridecanediamine (TTDA). software (PerkinElmer) in order to determine the absorbance value from which the carbonyl and amide concentrations, the main oxidation products, were calculated according to the method defined elsewhere [13].

\subsubsection{Mechanical properties}

Changes of mechanical properties during the oxidation of epoxy/amine have been followed by tensile testing on an Instron ${ }^{\circledR}$ 5881 machine. Dumbells samples have been obtained by cutting $100 \mu \mathrm{m}$ films. The effective zone has a dimension of $30 \mathrm{~mm}$ length and $4 \mathrm{~mm}$ width for DGEBA/TTDA and $10 \mathrm{~mm}$ length and $2 \mathrm{~mm}$ width for DGEBA/IDPA and DGEBU/IPDA. The crosshead speed was at $1 \mathrm{~mm} / \mathrm{min}$ was constant during the test and a $100 \mathrm{~N}$ cell was used. Tests have been performed in a controlled environment at $23{ }^{\circ} \mathrm{C}$ on five samples.

\subsubsection{Mass loss}

Weight changes have been monitored during the thermal oxidation of epoxy resin thanks to the Dual Range XS105 scale from Mettler Toledo with an accuracy of $\pm 0.01 \mathrm{mg}$. Those measurements have been duplicated on two samples with an initial mass of approximately $100 \mathrm{mg}$.

\subsubsection{Glass transition measurement}

Differential scanning calorimetry measurements were made with a DSC Q1000 (TA Instruments). Samples with mass ranging between 3 and $5 \mathrm{mg}$ are sealed in aluminum pans were heated from $0^{\circ} \mathrm{C}$ to $250^{\circ} \mathrm{C}$ at a $10^{\circ} \mathrm{C} / \mathrm{min}$ ramp under nitrogen flow $(50 \mathrm{ml} / \mathrm{min})$. Results were interpreted using TA Analysis software. DSC analyses were done to check the total cure of samples and to measure the value of the glass transition temperature of aged samples. $T_{g}$ values were measured during the second heating ramp (i.e. after having removed the thermal history of samples). Two samples of the same resin have been analyzed for each exposure time to control measurements reproducibility.

\subsubsection{Sub glass mobility}

To put in evidence sub glass transition, i.e. $\beta$ transition, dynamical mechanical analysis (DMA) measurements were performed between -100 and $40{ }^{\circ} \mathrm{C}$ at $1 \mathrm{~Hz}$ on films samples. For this purpose a DMA Q800 from TA instruments was used in tension mode.

\section{Results}

\subsection{Mechanical properties changes}

To put evidence drop of plastic deformation by oxidation, samples were characterized by classical tensile tests up to failure at room temperature. Fig. 2 shows stress-strain curves for all epoxy networks during exposure at $110{ }^{\circ} \mathrm{C}$. The stress-strain curves show a classical shape for epoxies [14-16] from which the strain at break was determined to monitor plastic deformation.

First of all, for DGEBA/IPDA and DGEBA/TTDA networks (Fig. 2a and $b$ ), a decrease of strain at break is associated to a modulus increase up to complete embrittlement whereas stress-strain changes for DGEBU/IDPA are clearly more complex.

First, a modulus increase is observed during thermal oxidation in the case of DGEBA/IPDA and DGEBA/TTDA. This phenomenon, so called anti-plasticization phenomenon, has already been observed during the epoxy cured with aromatic amine during oxidation [1] where modulus increase is related to decrease in local mobility associated to $\beta$ transition.

Strain at break changes clearly shows an embrittlement process in the case of DGEBA/IPDA and DGEBA/TTDA whereas strain at break 

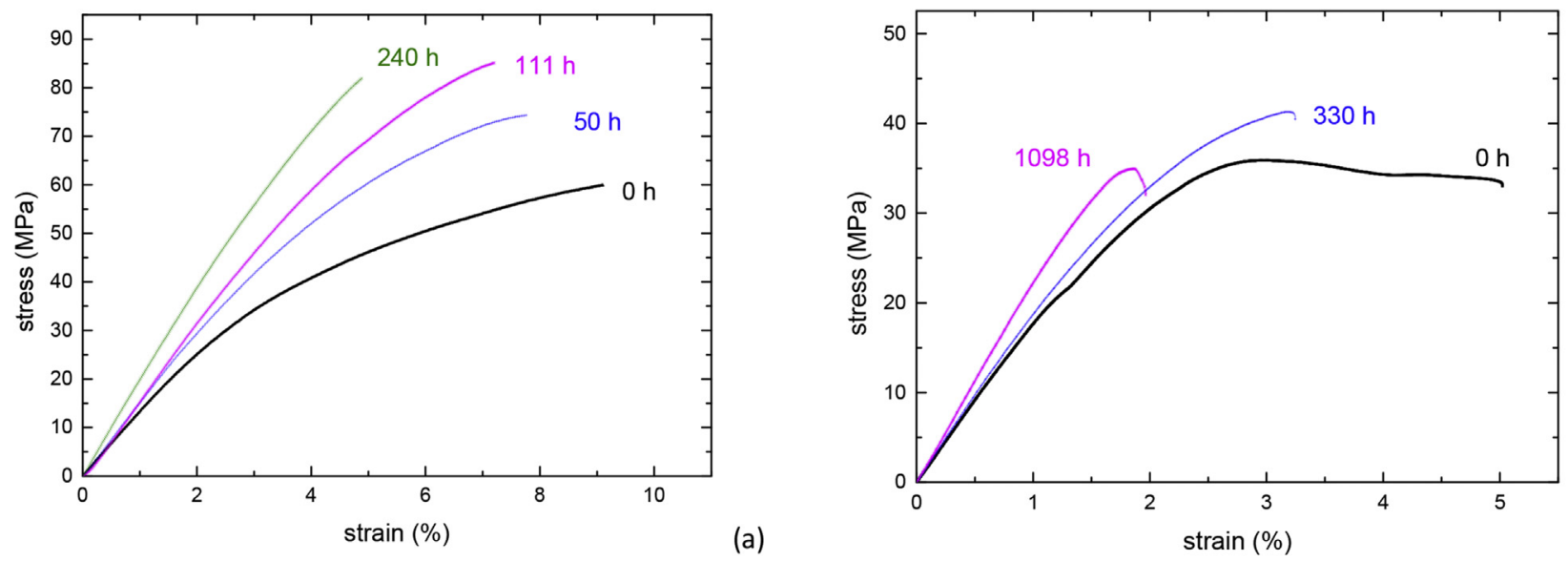

(b)

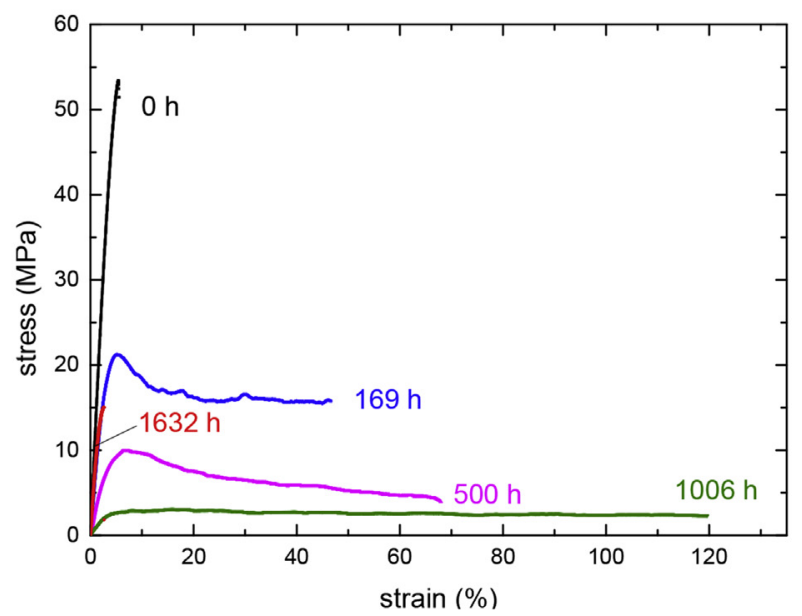

Fig. 2. Stress-strain curves of (a) DGEBA/IPDA, (b) DGEBA/TTDA and (c) DGEBU/IPDA after several aging times.

changes for DGEBU/IPDA are surprisingly more complicated. To put in evidence the embrittlement process for each system, strain at break values as a function of exposure time are reported in Fig. 3:

- for DGEBA/IPDA, it decreases continuously. The time at which strain at break is half is initial value is ca $200 \mathrm{~h}$.

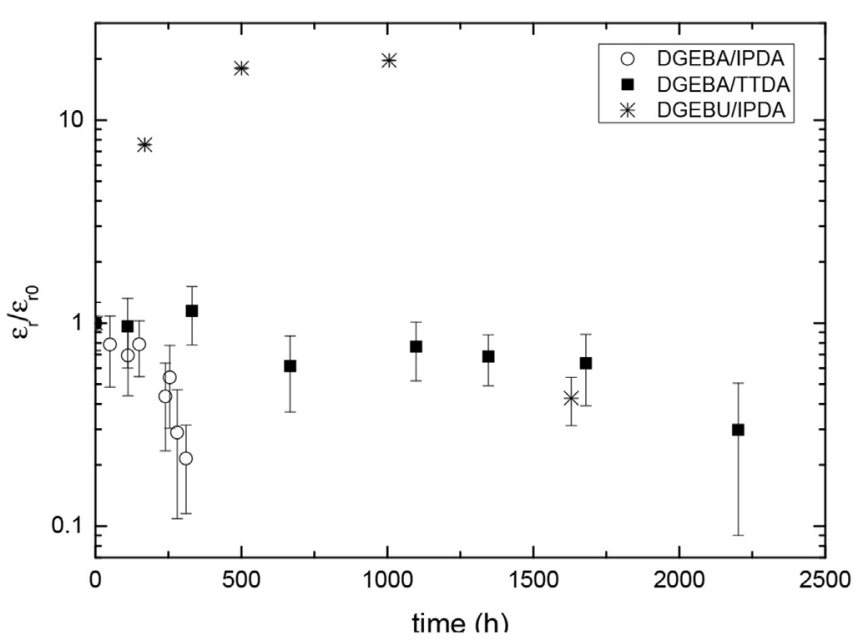

Fig. 3. Changes of mechanical properties: strain at break as a function of exposure time.
- for DGEBA/TTDA, the initially low strain at break value decreases at a low rate. The time at which $\varepsilon_{\mathrm{R}}=\varepsilon_{\mathrm{R} 0} / 2$ is ca $2200 \mathrm{~h}$.

- last, DGEBU/IPDA displays the most surprising trend: $\varepsilon_{\mathrm{R}}$ increases first very strongly and reaches values ca $100 \%$. After a sort of plateau, it decreases to a value close to $\varepsilon_{\mathrm{R} 0} / 2$ after ca $1630 \mathrm{~h}$

\subsection{Mass changes vs embrittlement}

In the introduction part, we have mentioned that mass loss is often used as a tracer for embrittlement. In other words, it is proposed that samples become brittle when mass loss exceeds $10 \%$. To check the validity of this assumption, we have followed mass changes during exposure in the same conditions. Mass changes as a function of exposure time are displayed in Fig. 4. In this latter, characteristic time for embrittlement (time for $\varepsilon_{R} \sim \varepsilon_{R 0} / 2$ ) is also reported for each networks by an arrow.

According to Fig. 4, DGEBU/IPDA displays an important mass loss (more than $20 \%$ after $1000 \mathrm{~h}$ of exposure at $110{ }^{\circ} \mathrm{C}$ ). This network is by far the most unstable system from the mass loss point of view. Indeed, embrittlement occurs at a mass loss close to $2 \%$ and $12 \%$ for DGEBA/IPDA and DGEBA/TTDA respectively.

As a result, it is obvious there is no direct correlation between an only one value of mass loss and the embrittlement time for the three systems under investigation. It means that the three systems studied here differ by the consequences on oxidation on the architecture of the network that will be studied below. 


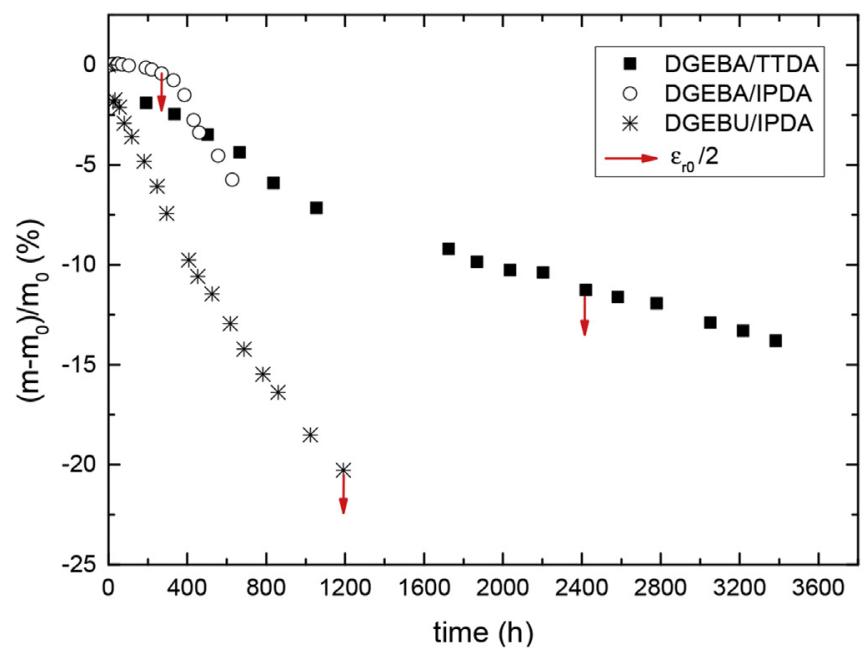

Fig. 4. Mass changes under atmospheric air at $110{ }^{\circ} \mathrm{C}$. Arrows indicate the embrittlement time.

\subsection{Glass transition changes vs embrittlement}

During oxidation, it is expected that epoxy network undergoes macromolecular changes during oxidation since a chain scission process occurs. Since it is challenging to detect the chain scissions in networks, measurement of glass transition temperature is particularly interesting since $T_{g}$ is related to the concentration in elastically active chains $[14,17]$, which decreases with chain scissions and increases with crosslinkings. $\mathrm{T}_{\mathrm{g}}$ changes during exposure and characteristic time for embrittlement (arrow) are reported in Fig. 5, which shows:

- DGEBA/IPDA displays a significant $\mathrm{T}_{\mathrm{g}}$ drop revealing a predominant chain scission process.

- DGEBA/TTDA displays a significant $T_{g}$ increase revealing a predominant crosslinking process.

- DGEBU/IPDA show first a slight $\mathrm{T}_{\mathrm{g}}$ drop followed by an increase. These changes can be attributed to chain scission events at low degree of conversion followed by a majority crosslinking process.

Interestingly, it appears the common point of both networks which undergo crosslinking (DGEBA/TTDA and DGEBU/IPDA) is the

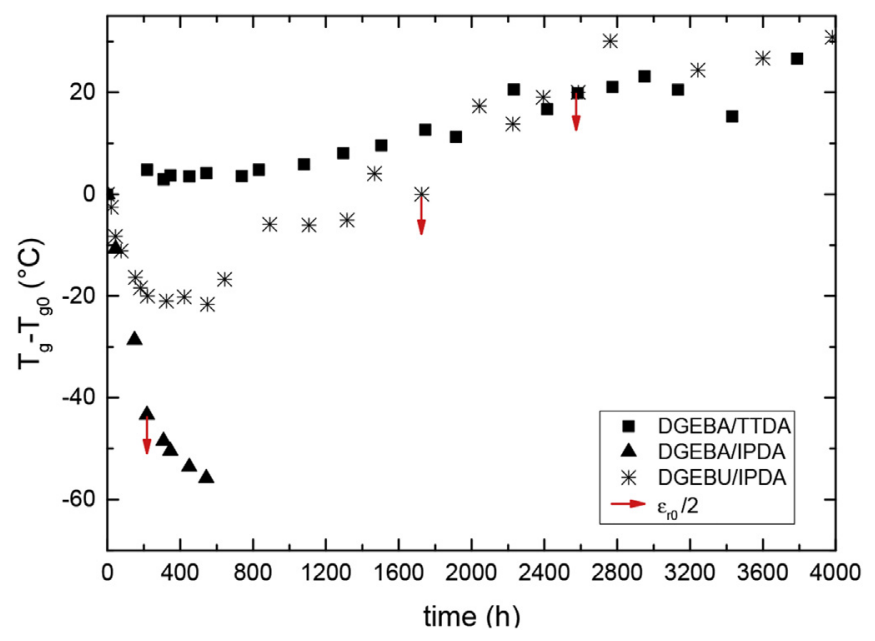

Fig. 5. $\mathrm{T}_{\mathrm{g}}-\mathrm{T}_{\mathrm{g} 0}$ changes versus time at $110{ }^{\circ} \mathrm{C}$ in air (arrows indicate embrittlement time). presence of methylenic sequences. A quantitative study and mechanism proposals of all these aspects can be found elsewhere [13].

\subsection{Sub-glassy transition}

Since two epoxy networks (DGEBA/IPDA and DGEBA/TTDA) remain in glassy state at room temperature even after oxidation process, it seems to us that sub-glass transition (so called $\beta$ transition) has to be investigated for both systems. Tan $\delta$ spectra obtained by DMA are shown in Fig. 6 for several exposure times.

First, a clear $\beta$ transition is put in evidence between -60 and $-20^{\circ} \mathrm{C}$ for both epoxy networks. Secondly, it appears that $\tan \delta$ amplitude decreases clearly for exposure times increasing. These spectra modifications could be associated to oxidation DGEBA segments. Indeed hydroxypropylether groups in DGEBA can be easily oxidized since they contain some unstable sites such as $\mathrm{CH}$ groups or $\mathrm{CH}_{2}$ groups in alpha position of heteroatoms [18].

\section{Discussion}

The main objective of this study is to propose mechanisms responsible for embrittlement process during oxidation. In terms of structure-property relationships, different approaches have been proposed in the literature to relate macromolecular architecture and failure properties: gap between $\mathrm{T}_{\mathrm{g}}$ and temperature for mechanical testing, molar mass between crosslinks mechanically active $\left(\mathrm{M}_{\mathrm{C}}\right)$ or sub glass transition intensity. To investigate the most relevant parameter, in other words relevant whatever the epoxy

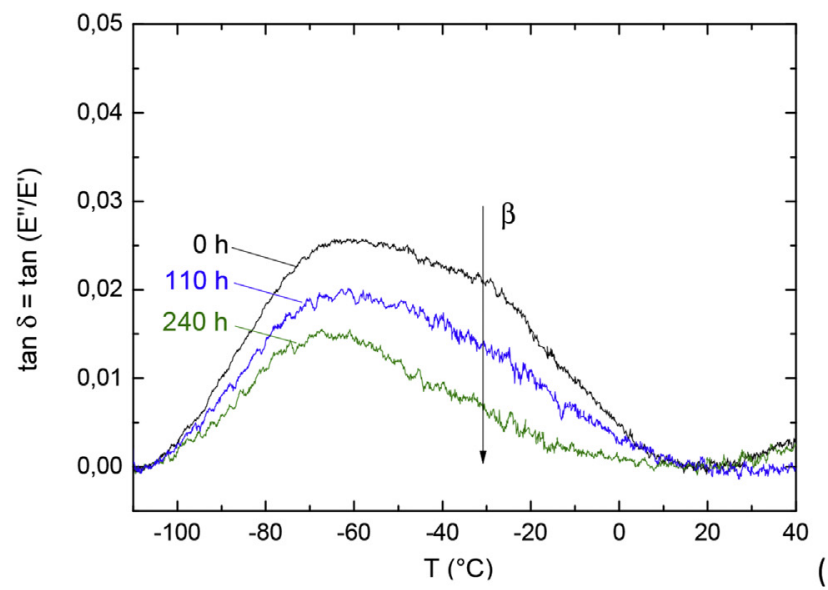

(a)

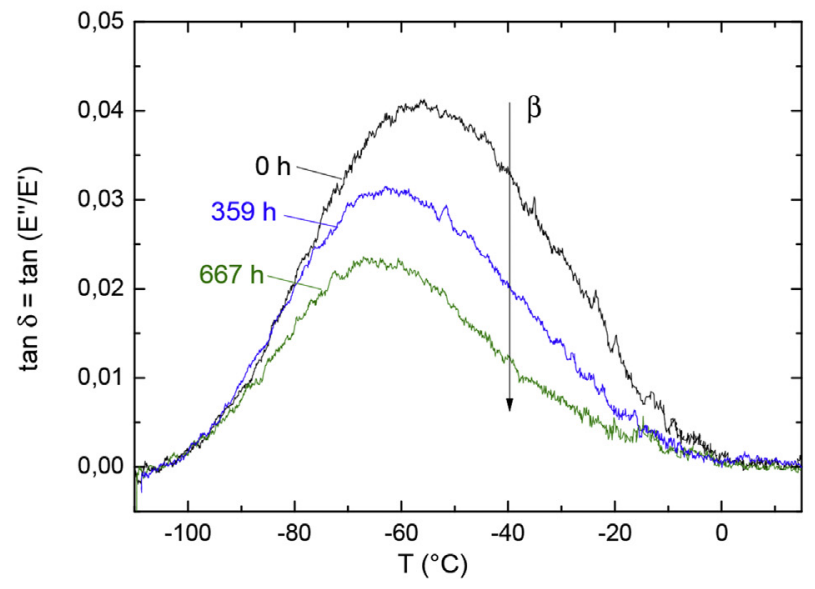

(b)

Fig. 6. Tan $\delta$ spectra during exposure at $110^{\circ} \mathrm{C}$ for (a) DGEBA/IPDA and (b) DGEBA/TTDA 
networks and the macromolecular modifications (chain scission or crosslinking) occurring during oxidation, we propose here to check out these three approaches successively.

\subsection{Gap between $T_{g}$ and temperature for mechanical testing}

To check out the first approach, strain at break has been plotted as a function of difference between $T_{g}$ measured and imposed temperature for tensile testing, room temperature (RT) in this study (Fig. 7). First, since initial $T_{g}-T_{R T}$ value for DGEBU/IPDA system is below $30{ }^{\circ} \mathrm{C}$ and decreases below $20{ }^{\circ} \mathrm{C}$ during oxidation up to $1000 \mathrm{~h}$ time of exposure, the mechanical behavior of this system tends to a rubbery behavior which explains large deformation (see for instance the stress-strain curve at $1006 \mathrm{~h}$ in Fig. 2c). At high oxidation level, the $T_{g}-T_{R T}$ increase leads to return to a glassy state and thus to strain at break values. It is noteworthy that the particular DGEBU/IPDA behavior during oxidation requires low initial $T_{\mathrm{g}}-\mathrm{T}_{\mathrm{RT}}$ value and a chain scission followed by a crosslinking mechanism.

In the case of DGEBA/TTDA network, even if the gap at the initial state is low $\left(45^{\circ} \mathrm{C}\right)$, this gap is inversely proportional to strain at break. In a same time, strain at break drops with the gap value initially close to $140{ }^{\circ} \mathrm{C}$ for the DGEBA/IPDA. As a result, the gap between $\mathrm{T}_{\mathrm{g}}$ and $\mathrm{RT}$ is not a common feature to explain embrittlement for both systems.

\subsection{Molar mass between crosslinks}

It has been proposed that properties at failure are proportional to $M_{C}^{1 / 2}$ with $M_{C}$ average molar mass between mechanically active crosslinks [9]. This relationship has been also experimentally validated for rubbers and is based on the fact that strain at break is related to maximum stretching of chains between crosslinks. The failure then occurs when chain stretching reaches its limit of chain extensibility defined as the square root of the number of crosslinks [19]. One can notice this approach in the case of glassy networks implies that large deformation is related to cooperative motions.

To assess $M_{C}$ values in our case, a possible way is to use DiMarzio's approach to estimate crosslink density (n) as following:

$T_{g}=\frac{T_{g l}}{1-\left(K_{D M} F n\right)}$

With $K_{D M}$ is the DiMarzio's constant ca 2.91 for epoxy/amine

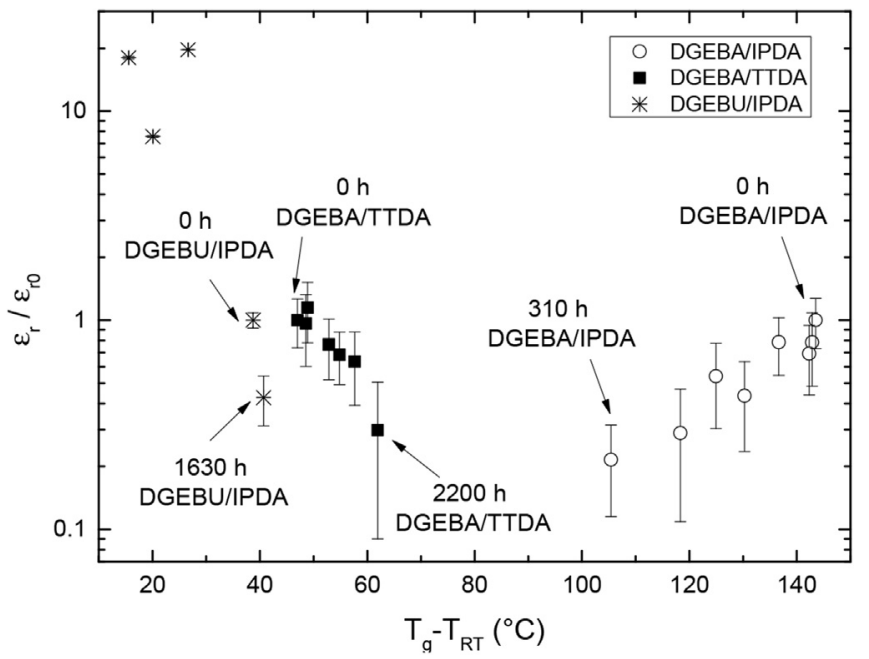

Fig. 7. Strain at break as a function of $T_{g}-T_{R T}$ during exposure at $110{ }^{\circ} \mathrm{C}$ for all networks ( $T_{R T}$ is the room temperature). trifunctional networks [20], $\mathrm{n}$ is the crosslink density $\left(\mathrm{mol} \mathrm{kg}^{-1}\right), \mathrm{T}_{\mathrm{gl}}$ is the glass transition of the corresponding « virtual » linear polymer and $\mathrm{F}$ is the Flex parameter $\left(\mathrm{kg} \mathrm{mol}^{-1}\right)$ related to the molar mass per flexible bond. Validity and physical meaning for the networks under study have been reviewed in Refs. [20,21].

Molar mass between crosslink $\left(\mathrm{M}_{\mathrm{C}}\right)$ can then be obtained from crosslink density ( $\mathrm{n})$ by:

$M_{C}=\frac{2}{f n}$

Where $\mathrm{f}$ is the network functionality equal to 3 in our case.

In Fig. 8, we have reported strain at break as a function of $\mathrm{M}_{\mathrm{C}}^{1 / 2}$. Concerning DGEBA/TTDA networks, a good correlation is obtained. However, DGEBA/IPDA follows an opposite trend: strain at break decreases with $\mathrm{M}_{C}$ increasing. As a result, even if this approach could be consistent for DGEBA/TTDA network possibly because its low $\mathrm{T}_{\mathrm{g}}$ value promotes cooperative motions, DGEBA/IPDA network shows a counterexample leading to conclude that $M_{C}$ is not the relevant parameter to monitor embrittlement.

\subsection{Sub glass transition intensity}

According to previously published results [22] evidencing that impact strength is governed by sub glass transition so called $\beta$ transition, sub glass transition depletion could be associated to strain at break (and related quantities) decrease [23-26]. To check out this scenario, Fig. 9 below shows strain at break as a function of the intensity (area) of the $\beta$ transition. It is observed that the plastic deformation decreases with the area the $\beta$ transition. This scenario thus appears valid to describe not only the embrittlement of DGEBA/TTDA but also, and especially, the embrittlement of DGEBA/ IPDA. However, the linear characteristic for this relationship between ductility and $\beta$ transition amplitude needs to be confirmed in the future.

\section{Conclusions}

By following physical modifications of three epoxy amine networks during oxidation, we have investigated the most relevant physical parameter responsible for embrittlement. Among these epoxy systems, DGEBA/TTDA has a low initial $\mathrm{T}_{\mathrm{g}}$ and undergoes mainly crosslinking whereas DGEBA/IPDA shows a relatively high

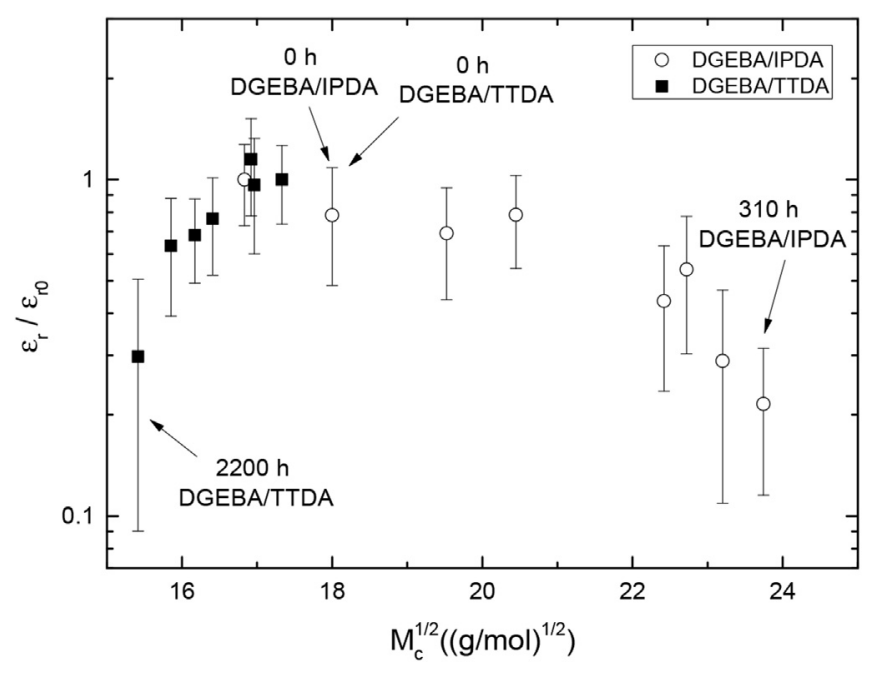

Fig. 8. Strain at break as a function of $M_{C}^{1 / 2}$. 


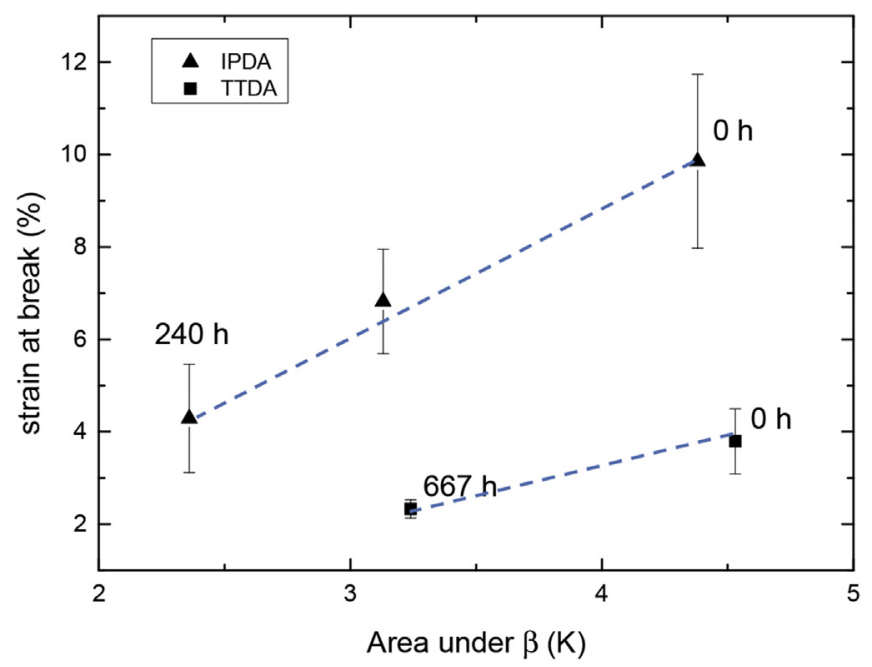

Fig. 9. Strain at break as a function of $\beta$ transition amplitude.

$\mathrm{T}_{\mathrm{g}}$ and undergoes mainly chain scission. The third chosen system (DGEBU/IPDA) has an initial $\mathrm{T}_{\mathrm{g}}$ close to room temperature and shows a chain scission process followed by a crosslink process at high oxidation level. Firstly, it has been proven that mass changes cannot be considered as a good parameter to monitor properties at failure. Indeed, DGEBA/IPDA becomes brittle for a mass loss close to $2 \%$, embrittlement of DGEBA/TTDA occurs at $12 \%$.

To put in evidence the relevant parameter according to different approaches proposed in the literature, we have followed $T_{g}$ changes focusing especially on the gap between $T_{g}$ and temperature of tensile testing $\mathrm{T}_{\mathrm{RT}}$. It appears that only strain at break changes for DGEBU/IPDA can be explained by the $T_{g}-T_{R T}$ evolution. To investigate DGEBA/TTDA and DGEBA/IPDA embrittlement, two physical parameters have been correlated to strain at break drop. The first one is the molar mass between crosslink $M_{C}$ calculated from $T_{g}$ by DiMarzio's theory and the second one is the intensity of peak associated to $\beta$ transition. As a result, $\beta$ transition disappearance during oxidation is the only molecular modification which can be associated to embrittlement for both epoxy systems. This finding shows clearly that embrittlement is not directly associated to chain scission or crosslinking mechanism. Knowing that the $\beta$ transition assigned to hydroxypropylether groups local mobility is responsible for ductility, embrittlement appears to be governed by oxidation of these groups in the DGEBA segment.

\section{Acknowledgements}

ANRT (CIFRE $\mathrm{N}^{\circ}$ 2013/0356) is gratefully acknowledged for financial support.

\section{Appendix}

We are here interested in discussing on the relative weight loss observed in each kind of epoxy/amine system so as to try to justify them from a structural point of view.

For that purpose, we will first try to quantify the occurrence of a volatile compound from chain scissions. In the aim of simplicity, we will first only consider that only $\mathrm{CH}_{2}$ in $\alpha$ position of nitrogen are reactive (having in mind that the effect of the other $\mathrm{CH}$ groups is isopropanol will involve the same kind of effects).

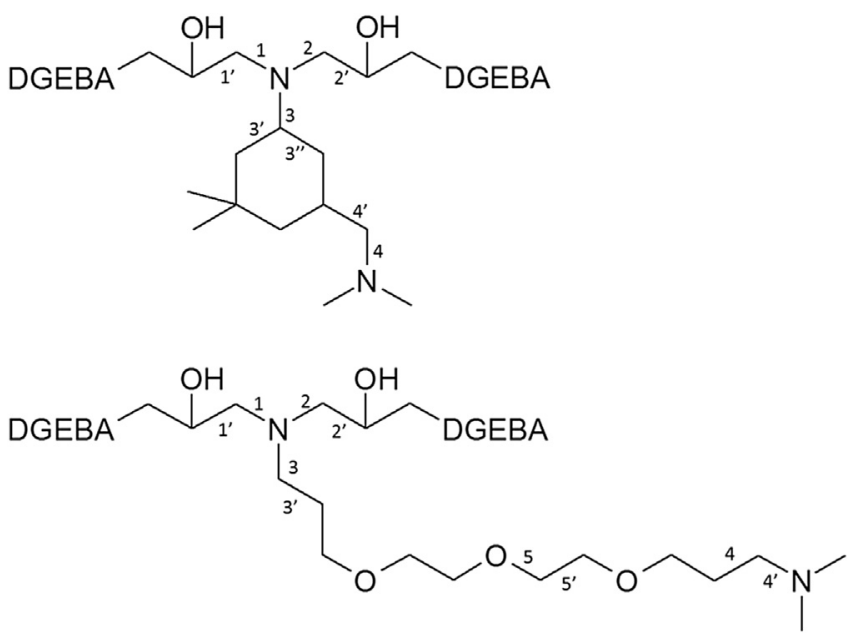

From Table 1, it can thus be estimated that 8 scissions in DGEBA/ IPDA are needed to generate 1.66 volatiles. This number may be lower if we consider that the tertiary $\mathrm{C}-\mathrm{H}$ in $\alpha$ position of nitrogen rather yields to scissions of $3^{\prime}$ and $3^{\prime \prime}$ bonds instead of scission of 3 bond (which would give $\mathrm{a}>\mathrm{N}^{\circ}$ radical, that was not observed, to the best of our knowledge, in epoxy oxidation).

Table 1

Effect of chain scission on volatile generation in DGEBA/IPDA.

\begin{tabular}{lllll}
\hline 1 or $1^{\prime}$ & 2 or $2^{\prime}$ & 3 or $3^{\prime}$ or $3^{\prime \prime}$ & 4 or $4^{\prime}$ & propability of volatile generation \\
\hline$*$ & $*$ & $*$ & & $1 / 3$ \\
$*$ & $*$ & & $*$ & 1 \\
& & $*$ & $*$ & $1 / 3$ \\
\hline
\end{tabular}

In DGEBA/TTDA (Table 2), the generation of volatile compounds is favored for at least two reasons:

- the absence of tertiary $\mathrm{CH}$ which favors the yield in scissions of elastically active chains

- the participation of $\mathrm{CH}_{2}$ in $\alpha$ position of oxygen

Table 2

Effect of chain scission on volatile generation in DGEBA/TTDA.

\begin{tabular}{llllll}
\hline 1 or $1^{\prime}$ & 2 or $2^{\prime}$ & 3 or $3^{\prime}$ or $3^{\prime \prime}$ & 4 or $4^{\prime}$ & 5 or $5^{\prime}$ & propability of volatile generation \\
\hline$*$ & $*$ & $*$ & & & 0 \\
$*$ & $*$ & & $*$ & & 1 \\
& & $*$ & $*$ & & 1 \\
& & $*$ & $*$ & $*$ & 1 \\
$*$ & $*$ & & & $*$ & 1
\end{tabular}

Last, in DGEBU/IPDA, the previous reasoning would suggest that yield of volatile would be the same than in DGEBA/IPDA. However, the possibility of chain scissions occurring on both isopropanol functions of the same DGEBU group is another significant source for volatiles.

\section{References}

[1] J.-S. Chen, C.K. Ober, M.D. Poliks, Y. Zhang, U. Wiesner, C. Cohen, Controlled degradation of epoxy networks: analysis of crosslink density and glass transition temperature changes in thermally reworkable thermosets, Polymer 45 (2004) 1939-1950. 
[2] S. Terekhina, M. Mille, B. Fayolle, X. Colin, Oxidation induced changes in viscoelastic properties of a thermostable epoxy matrix, Polym. Sci. Ser. A 55 (10) (2013) 614-624.

[3] R.J. Morgan, F.-.M. Kong, C.M. Walkup, Structure-property relations of polyethertriamine-cured bisphenol-A-diglycidyl ether epoxies, Polymer 25 (1984) 375-386.

[4] A.C. Grillet, J. Galy, J.-F. Gérard, J.-P. Pascault, Mechanical and viscoelastic properties of epoxy networks cured with aromatic diamines, Polymer 32 (1991) 1885-1891.

[5] A.E. Mayr, W.D. Cook, G.H. Edward, Yielding behaviour in model epoxy thermosets - I. Effect of strain rate and composition, Polymer 39 (1998) 3719-3724.

[6] F. Fernandez-Nograro, A. Valea, R. Llano-Ponte, I. Mondragon, Dynamic and mechanical properties of DGEBA/poly(propylene oxide) amine based epoxy resins as a function of stoichiometry, Eur. Polym. J. 32 (1996) 257-266.

[7] F.G. Garcia, B.G. Soares, V.J.R.R. Pita, R. Sánchez, J. Rieumont, Mechanica properties of epoxy networks based on DGEBA and aliphatic amines, J. Appl. Polym. Sci. 106 (2007) 2047-2055.

[8] E. Espuche, J. Galy, J.-F. Gérard, J.-P. Pascault, H. Sautereau, Influence of crosslink density and chain flexibility on mechanical properties of model epoxy networks, Macromol. Symp. 93 (1995) 107-115.

[9] J.D. LeMay, F.N. Kelley, Structure and ultimate properties of epoxy resins, In: Epoxy Resins and Composites III (ed. Dušek, K.), Adv. Polym. Sci. 78 (1986) $115-148$.

[10] E. Urbaczewski-Espuche, J. Galy, J.-F. Gerard, J.-P. Pascault, H. Sautereau, Influence of chain flexibility and crosslink density on mechanical properties of epoxy/amine networks, Polym. Eng. Sci. 31 (1991) 1572-1580.

[11] L. Heux, J.L. Halary, F. Lauprêtre, L. Monnerie, Dynamical mechanical and $13 \mathrm{C}$ n.m.r. investigations of molecular motions involved in the $\beta$ relaxation of epoxy networks based on DGEBA and aliphatic amines, Polymer 38 (8) (1997) 1767-1778.

[12] E. Ernault, E. Richaud, B. Fayolle, Thermal-oxidation of epoxy/amine followed by glass transition temperature changes, Polym. Degrad. Stab. 138 (2017) 82-90.

[13] E. Ernault, E. Richaud, B. Fayolle, Thermal oxidation of epoxies: influence of diamine hardener, Polym. Degrad. Stab. 134 (2016) 76-86.
[14] O. Sindt, J. Perez, J.F. Gerard, Molecular architecture-mechanical behaviour relationships in epoxy networks, Polymer 37 (1996) 2989-2997.

[15] F. Lapique, K. Redford, Curing effects on viscosity and mechanical properties of a commercial epoxy resin adhesive, Int. J. Adhesion Adhesives 22 (4) (2002) 337-346.

[16] N. Tian, R. Ning, J. Kong, Self-toughening of epoxy resin through controlling topology of cross-linked networks, Polymer 99 (2016) 376-385.

[17] N. Rasoldier, X. Colin, J. Verdu, M. Bocquet, L. Olivier, L. Chocinski-Arnault, M.C. Lafarie-Frenot, Model systems for thermo-oxidised epoxy composite matrices, Compos. Part A Appl. Sci. Manuf. 39 (2008) 1522-1529.

[18] H. Matsui, C.A. Schehr, J.J. Valentini, J.N. Weber, Resonance Raman Spectroscopy investigation of the mechanism and kinetics of the degradation of $\mathrm{N}, \mathrm{N}-$ hexamethylene bishexamide, a nylon 6,6 model compound, Polymer 42 (2001) 5625-5632.

[19] L.R.G. Treloar, The Physics of Rubber Elasticity, Oxford University Press, 1975

[20] V. Bellenger, J. Verdu, E. Morel, Effect of structure on glass transition temperature of amine crosslinked epoxies, J. Polym. Sci. Part B Polym. Phys. 25 (1987) 1219-1234.

[21] Y.-G. Won, J. Galy, J.-P. Pascault, J. Verdu, Prediction of the glass transition temperature of cycloaliphatic amine-epoxy networks, J. Polym. Sci. Part B Polym. Phys. 29 (1991) 981-987.

[22] T. Kamon, H. Furukawa, Curing mechanisms and mechanical properties of cured epoxy resins, In: Epoxy resins and Composites IV (ed. Dušek, K.), Adv. Polym. Sci. 80 (1986) 173-202.

23] M. Pecora, Y. Pannier, M.-C. Lafarie-Frenot, M. Gigliotti, C. Guigon, Effect of thermo-oxidation on the failure properties of an epoxy resin, Polym. Test. 52 (2016) 209-217.

[24] J. Decelle, N. Huet, V. Bellenger, Oxidation induced shrinkage for thermally aged epoxy networks, Polym. Degrad. Stab. 81 (2003) 239-248.

[25] B.J. Anderson, Thermal stability of high temperature epoxy adhesives by thermogravimetric and adhesive strength measurements, Polym. Degrad. Stab. 96 (2011) 1874-1881.

[26] F. Daghia, F. Zhang, C. Cluzel, P. Ladevèze, Thermo-mechano-oxidative behavior at the ply's scale: the effect of oxidation on transverse cracking in carbon-epoxy composites, Compos. Struct. 134 (2015) 602-612. 